\title{
Inventing Nature: Re-writing Time and Agency in a More-than-Human World MICHELLE BASTIAN
}

In her essay 'Nature in the Active Voice' Val Plumwood makes the call for writers to engage in 'the struggle to think differently' (128). Specifically, she calls writers to engage in the task of opening up an experience of nature as powerful and as possessing agency. She argues that such a task should not be understood as a literary self-indulgence, but as 'a basic survival project' (128). In this article, I will argue that a critical component of opening up who or what can be understood as possessing agency involves challenging the conception of time as linear, externalised and absolute, particularly in as much as it has guided Western conceptions of process, change and invention.

Initially, I discuss the work of a Carol Greenhouse, who argues that social conceptions of time can be read as theories of agency. ${ }^{1}$ That is, she suggests that time concepts express collective understandings of how change happens and how the power to enact change is distributed. I then suggest that this interconnection between time and agency can be seen in Plumwood's own work. That is, in challenging Western accounts of agency, I argue that she also challenges Western accounts of linear time, which isolate the capacity for agency within the human.

Thus, in seeking to respond to Plumwood's call to think differently, the question becomes: what kind of writing would enable a fundamental re-thinking of agency without, however, ignoring the way Western notions of agency have been shaped by linear accounts of time? One promising approach is that offered by the work of Jacques Derrida. I first locate the possibility of re-writing time and agency in the experiential aspects of his writing, which I argue interrupt both the reader's sense of agency and linear models of reading. But further, I seek to connect Derrida's work directly with Plumwood's by examining how

\footnotetext{
1 My discussion focuses particularly on what sociologists and anthropologists have termed 'social time'. This term was first introduced by Durkheim and according to Greenhouse can now be defined as the study of 'the ways in which social experience defines the forms, meanings and relevance of time' (25). Importantly, I will not be discussing time either in terms of an 'objective time' or of a purely 'subjective time', a traditional philosophical distinction which I have questioned elsewhere (Bastian 25-31). This is, in part, because both approaches fail adequately to deal with the wide variety of symbolic, normative, and evaluative aspects of temporality that are given to us within sociality.
} 
his deconstruction of the Western concept of invention may enable another account of creative change that could reshape what counts as 'agency' within the Anthropocene.

\section{Time as agency}

In order to draw out connections between the problem of agency and concepts of time, I am utilising a broad notion of agency that is drawn from the work of anthropologist Carol Greenhouse. Her work is significant in that it enables a critical approach to the way agency is predominantly understood in the West. Specifically, Greenhouse argues that 'time articulates people's understandings of agency: literally, what makes things happen and what makes acts relevant in relation to social experience, however conceived' (1). In doing so, Greenhouse challenges more common understandings that suggest that 'agency universally involves issues of intention (whether or not the intention originated with the actor) and will' (80). One of the problems with such assumptions is that they determine "in advance that what "matter" about agency are individual effects on society' (81). This assumption skews understandings of agency by suggesting that Western understandings of it are neutral.

In contrast, Greenhouse contends that agency should be understood as referring to 'the broad and highly varied meanings people attach to questions of possibility, causation, and relevance around the world' (183). Or to put it another way, she understands agency as referring to 'people's goals, together with their broader sense of what is possible and of what relevance is about, even if their understanding of relevance excludes their own experiences from the story of the world' (234). So rather than assuming that individual self-directed actions are of most relevance when explaining how significant changes occur, Greenhouse suggests that there are a variety of ways of constructing explanatory causal chains. While in some cases an individual's actions, regardless of rank, may be thought to be significant, in other cases, only the actions of political or religious leaders are relevant. Alternatively, it may be the behaviour of a group as a whole that shapes what is possible, or agency may be a power reserved only for deities, natural processes, or inaccessible unconscious drives.

Importantly, given the particular focus of this essay, while Greenhouse's account of agency does focus on human goals, in dissociating agency from intention and will, and by extending the question of relevance beyond the human, her broader account suggests that agency need not necessarily be restricted to humanity. Crucially, her work suggests that the individualistic and humanist notion of agency that dominates the Western tradition is not simply what agency is. Rather, she argues that this account of agency is shaped by the socially produced articulations of time that underlie it. 
Greenhouse's broader account of agency suggests that when a culture is guided by a different temporal schema, agency can be understood quite differently. To briefly provide some examples, I will outline her account of the connections between time and human agency in the classic Western anthropological typology of time as 'timeless', 'cyclical' or 'linear'. In discussing these traditional taxonomies, even while challenging them ${ }^{2}$, Greenhouse initially argues that 'agency can be seen to have many sources and many different concentrations in the human world, from highly concentrated to highly diffuse' (93). Indeed she argues that what best distinguishes between systems of time is not their differing understandings of how time 'flows,' but rather how change is thought to occur, that is, how the power of agency is distributed among possible human or non-human actors. For example, she suggests that 'timeless' or 'shapeless' times 'formulate agency as having been generated in a single burst apart from the social sphere of experience' (86). While this 'single burst' of agency may intervene in day-to-day life, it is not distributed to all social actors at all moments. Cyclical times distribute 'agency in one or more finite clusters that include the lived in world' (86). For example, in the cyclical notion 'to everything there is a season,' the ability to act in certain ways is understood to be clustered within a specific part of time, or 'season'. One cannot act in any way that one would like at any time, rather only specific actions are thought to be viable at any specific moment. Finally, Greenhouse argues that 'linear' time ostensibly 'distributes agency most widely, dispersing its "original" creation (by God, or a big bang, or another potentiating force) to each individual' (86).

In discussing this temporal typology, Greenhouse notes that these accounts of time and agency are not mutually exclusive; rather there are always multiple ways of living time within any particular society. However, where one specific idealisation of time becomes hegemonic, this notion will also guide the hegemonic notion of agency. As such, Greenhouse's work raises the interesting question of whether Western accounts of agency focus on the ability of a self-conscious individual to achieve a previously articulated goal, not because this simply is agency, but because the notion of time as linear guides this understanding of how change happens. Specifically, her work suggests that the West's dominant account of agency is shaped by linear time's basis in the modification of present moments, where an idealisation of 'presence' underlies the idealisation of the

2 Greenhouse criticises the strong tendency to understand time through the use of geometric metaphors within the West, arguing that such metaphors are inadequate and limiting. For example, she points out that 'when cultural constructions of time rest on underlying notions of cyclicity, a cycle might be a pendulum, a static circle, a dynamic cycle, a spiral' (85). To claim that such notions are all 'circular' obscures the significant differences between each account. Further she argues that societies are referred to as 'timeless' not because there are in fact no concepts of time but 'because their representations of time do not appear geometric to a Western eye' (85). One example of work that explores alternative non-geometrical dynamics of time is that of Deborah Bird Rose (see, for example, 'To Dance' and Dingo Makes, especially 203-217). 
individual and its capacity for rational decision making. Importantly, her account enables one to begin to consider how attempts to reshape the concept of agency may be unknowingly restricted by underlying social concepts of time.

The importance of this last point can first be seen in the case of Western encounters with so-called 'timeless' societies. As anthropologist Alfred Gell has claimed, to categorise a community as without time is to suggest that its members 'do not believe that the world changes much or in very important ways, by contrast to [those with linear time scales] who are perhaps inclined to believe that the world changes constantly and in ways that matter a great deal' (36). Further, he explains that 'what seems to be meant by calling time "motionless" ... is the imperviousness of some process or institutional form to systemic change' (26). However, what Greenhouse's work suggests is that such societies are neither devoid of time, nor are they devoid of accounts of agency. Rather, their accounts of time and agency are not easily recognisable from within the framework of linear time. Thus it is from the particular perspective of Western societies that the classification 'timeless' is pronounced. To classify something as 'timeless' does not, therefore, mean that it escapes time altogether but, rather that, to those doing the classifying, a particular process or culture does not appear to change in significant or relevant ways. In this way, as I have explored more thoroughly elsewhere, notions of time can be used in a variety of ways to dismiss or misread different cultures (Bastian). ${ }^{3}$ However what is important in this context is how Western assumptions about time have fostered notions of nature as timeless, and as without agency.

\section{Nature's agency}

According to Bill McKibben, one of the reasons why the West has failed to respond adequately to the threat of climate change has been because of a confusion about time. That is:

though we know that our culture has placed our own lives on a demonic fast-forward, we imagine that the earth must work on some other timescale. The long slow accretion of epochs - the Jurassic, the Cretaceous, the Pleistocene-lulls us into imagining that the physical world offers us an essentially stable background against which we can run our race $(7){ }^{4}$

In treating nature as a stable background, we are, in a sense, claiming that the changes that do occur within nature are neither significant nor relevant. But further, when one understands time as agency, seeing nature as without

3 See also Johannes Fabian's seminal Time and the Other.

4 Thanks to Beth Seaton for bringing this quote to my attention. 
significant changes, without time, is to also see it as without agency. However, recognising nature's agency cannot amount to an attempt to incorporate nature within the smooth even flow of absolute time as it was conceived by Newton. This is because within linear time, what counts are individual wills, and, when combined with teleological or progressivist tendencies, rationally guided logical change. Indeed I would argue that reinterpreting the creative changes, possibilities and causalities that do occur within nature as agency is impossible if one attempts to integrate nature into the schema provided by linear time. Instead, it would appear that Plumwood's own work indicates that a shift in how agency is understood must be accompanied by a shift away from linear temporal models.

In the essay 'Nature as Agency,' Plumwood calls for a non-reductive understanding of nature as 'an active collaborative presence capable of agency and other mind-like qualities' (16). Such a task is doubly important as it links up with feminist and social justice concerns. As Plumwood explains, 'it has been possible to discount the agency of subordinated groups of humans by counting them or their agency as nature only because nature's agency is itself normally denied and backgrounded in Western culture' ('Nature as Agency' 20). Thus, as a critical concept within a variety of schemas of dominance she argues that 'the reconception of nature in agentic terms as a co-actor and co-participant in the world and its recognition in distributive terms is perhaps the most important aspect of moving to an alternative ethical framework' ('Nature as Agency' 16).

In analysing the conceptual structures that support Western conceptions of agency, Plumwood focuses particularly on the technique of hyper-separation, whereby the contributions of both subordinated humans and nature are backgrounded, or taken for granted. She argues that 'the One or Man of Property is able to assume the contribution of nature in the form of a continuing support base for production, accumulation and renewal, but to deny it in failing to recognise, and allow for, nature's reproduction and continuation' ('Nature as Agency' 9). Indeed she claims that it is dominant conceptions of agency that provide 'the conceptual means by which this simultaneous reliance and disavowal is accomplished' ('Nature as Agency' 14). One of the key characteristics of this notion of agency that she highlights draws on the Cartesian split between a mechanistic nature and a mind that possesses free will. That is, 'anthropocentric culture often endorses a view of the human as outside of and apart from a plastic, passive and "dead" nature which lacks agency and meaning' ('Nature as Agency' 12). The capacity for creating change is isolated from whatever is perceived as natural. Instead, as she argues in 'Nature in the Active Voice', the instigator of change is understood as 'a separate mechanism or intelligence driving the materially-reduced organism from outside, and it is to this external 
driver that true agency is attributed' (119). The task of re-imagining agency lies, therefore, in challenging both the externalisation of the rational human subject from nature, and the mechanisation of all that remains.

Interestingly, what is common to both the idealisation of rationality and the mechanistic reduction of nature is an idealisation of logically ordered linear processes, epitomised by the utilisation of clock metaphors in the work of Descartes, Leibniz and Spinoza. Despite their important differences, each philosopher utilised images of the clock to emphasise the underlying order of the mind and, alternatively, of the physical world. In part, this is perhaps due to the premier place the clock has in encouraging an understanding of time as an external constant that, firstly, is unmoved by human emotions, desires or fears, thus providing an idealised model for the rational mind as likewise unmoved. Secondly, in illustrating the supposedly steady even flow of 'absolute time,' as Newton called it, the clock also suggests that underneath the seeming chaos of multiply interacting social, biological and ecological processes there lies a logical linear time-line that charts a single all-encompassing movement from the past to the future. Nature thus becomes the expression of underlying logical physical laws that promise one day to be uncovered, enabling all natural systems to be predicted and managed. This account of time, which is often presented as a simple unit of measurement, and thus as asocial and free from the operations of power, is thus arguably an important foundation for the account of agency that itself supports the hyper-separation of nature and culture.

Indeed, in articulating an alternative understanding of agency, Plumwood's work appears to move away from the kinds of linear processes discussed above. What seems to be key is her effort to disconnect the concept of agency from a linear model within which the only significant and relevant changes are those that are planned and carried out by a rational subject in a logical and predictable manner. For example, one of the reasons why she critiques the model of 'production' as unsuitable for explaining humanity's relation to nature is because it would 'continue to suggest human control ... and seem especially inappropriate for those many cases where the outcome is neither planned nor anticipated by those responsible for it' ('Nature as Agency' 24). In her account then, unexpected and surprising changes should be recognised as having relevance and significance. Even further, Plumwood explores the possibility that evolution be understood as a form of agency. For instance, she asks 'why can't we see evolution, for example, as a form of testing and learning, like trial and error, a form of wisdom?' ('Nature in the Active' 125). This further suggests that Plumwood explicitly seeks to understand changes that are not driven by a single rational mind as significant and creative.

In contrast to the hegemonic Western conception of agency, Plumwood suggests that recognising nature as a sphere of agency may instead draw upon 
'more pluralistic and context-sensitive concepts of influence, interaction and mutuality' ('Nature as Agency' 23). Such an emphasis would indicate a shift away from understanding processes of change as being ultimately reducible to the single line of linear time. In 'Nature in the Active Voice' she suggests further shifts in how agency is understood. Specifically she muses over the possibility of seeing accident as 'creative non-human agency,' 'sound as voice,' and 'adaptation as intelligence' ('Nature in the Active' 125). In this way, she teases open the taken-for-granted connection between agency and rational deliberative forethought. It is this issue that I will take up specifically in my discussion of Derrida's account of invention. For the moment, however, I would like to suggest that it is precisely in opening up the possibility that agency need not be about the deliberate implementation of a series of pre-thought-out steps aiming towards a clarified goal, that Plumwood not only reworks the concept of agency, but also reshapes Western modes of conceptualising the flow of time.

\section{Re-writing time}

In 'Nature in the Active Voice', Plumwood emphasises the importance of challenging the West's 'most basic cultural narratives' (113). She calls for writers to open consumerist culture to self-criticism and to make it think more closely about its underlying assumptions. While other articles in this issue explore the possibilities of types of writing that could more properly be called literary, I would like to offer a reading of Derrida's writing as that which could help to address the questions of agency and of time. First, I will suggest that the experiential aspects of his writing enable a re-evaluation of the limits of the self-directed individual prized by traditional Western accounts of agency. Secondly, I explore how questions of change, possibility and causation (which are also questions of time) are reworked within an enigmatic framework that intertwines the capacity to bring about change with a necessary passivity in relation to significant change. Such questions arise throughout Derrida's work, particularly in those areas that most directly address key issues within environmental philosophy, such as the limit between human and non-human animals (see, for example, 'The Animal'). My particular interest, however, is in developing Plumwood's suggestion that evolution be understood as a manifestation of nature's agency. I will suggest that Derrida's reworking of the Western concept of invention, which has itself marked the limit between the human and non-human, provides new avenues into the question of agency that are not pre-determined by the imperatives of linear time.

To begin, one of the first ways we might see Derrida's writing as shifting Western understandings of agency and of time arises from the difficult and obscure nature of his work. That is, while its difficulties have been generally criticised for being elitist, exclusionary, or obscurantist, I would suggest that, within the context 
of human exploitation of nature, the experience of encountering a new (con) text that is impossible to master with a single glance (or single reading) offers something very important. This is particularly the case in an age where brevity and clarity are often uncritically valued. As Plumwood herself notes, 'public discussion in our society is dominated by the tyranny of narrow focus' ('Nature in the Active' 113). The complexities of Derrida's texts refuse this narrow focus or search for easy answers. As such, they offer the very practical lessons of patience, of developing complex stories, of the impossibility of mastery, and of the need to change oneself in order to ethically encounter the strange and the new. Above all, in countering the desire for immediate clarity, Derrida's work thwarts the desire for the world to be presented to the self in terms that are already familiar.

The experience of reading such texts has the capacity to shift experiences of time in a number of ways. Firstly, texts characterised by clarity do not take up one's time. They can be read and understood quickly. They present themselves. Secondly, even when one is referring to a longer text, where a certain amount of time must, of course, be taken, this time is not marked by confusion, by missteps or breaks. Rather one can chart one's progress in a fairly simple fashion. Chapter or page numbers regularly mark, not just the amount read, but the steady amount of increasing knowledge one has gained. Complex texts, on the other hand, demand one's time. One must learn to work at a slower pace in order to appreciate them. In this way they have the capacity to challenge the consumerist desire for immediate wish-fulfilment and also offer a counterpoint to the breakneck speed that has come to characterise the capitalist world.

Further, the different rhythm required to read Derrida's work, is not just slower, but could also be thought of as non-linear. One does not move smoothly from beginning to end. Instead of building a cumulative understanding as one progresses, Derrida's work requires one to wait patiently, collecting up one's experiences and only later gaining a better idea of how they might fit together. One could perhaps draw parallels with the Permaculture practice of observing one's environment for at least a year, learning the specificities of one's place before intervening. This attitude assumes that neither a text nor an environment is available immediately to an actor but must be experienced through time, in their different seasons, throughout their (and one's own) changes. It also assumes that one is encountering complex systems that need complex experiences and built up shared histories before one can hope to act productively within/or in relation to them.

Like the natural environment too, one must not treat the text as a timeless unchanging thing awaiting the action of the human. Indeed I am constantly amazed by the way in which Derrida's texts shift and change between readings. The supposedly passive, unchanging text, the work that is thought to help one 
escape death by maintaining a faithful unchanging record of one's thoughts, becomes mobile and creative. Not on its own, but within the mutuality, interactivity and influence that enframe another understanding of agency. This ability to change over time, to have something new to offer to the future is a deliberate feature of Derrida's work. In the interview, 'Negotiations', he claimed that he sought to 'enable a phrase to have an immediate effect and also a reserve, to say other things to others, later on' (28). He thus sought to enable multiple rhythms within his work, operating at different speeds, in recognition of responsibilities owed not only to those in the 'present' but those who have already died and those who are not yet born (see Spectres of Marx). There is therefore a certain unpredictability within his texts that does not allow one to understand them as impervious to change, to understand them as 'timeless'. This is a sense of extended time that is sorely needed in an era where present and future lives are sacrificed for short-term gains.

As mentioned above, key for Plumwood is questioning the dogma of human supremacy, connected with 'the need to see ourselves as more limited beings' ('Nature in the Active' 117). In challenging linear patterns of reading, Derrida's work has the capacity to provide a much needed experience of limitation. ${ }^{5}$ In doing so, it also provides another experience of agency (understood in the broad sense outlined above). That is, in reading his writing one experiences oneself as limited since one cannot grasp as much as one would like: the text exceeds the reader. ${ }^{6}$ The reader finds themselves in an environment that does not bend obligingly to their will. One cannot have what one wants in the moment one wants it. Further one does not achieve one's goals in a steady, accumulative way. Instead, flashes of understanding come by chance, or by accident; more a fortuitous gift than the guaranteed outcome of continuous application. This is quite different from what is usually understood as agency. Indeed the active work of reading is not experienced as mastery, but rather as an active passivity. One must strive for understanding, but one's goals are not achieved solely through one's own initiative. Indeed the very notion of achievement is transformed. One's active waiting finds satisfaction, not in something predictable, but in the surprising and the unexpected. Simple solutions, simple summaries do not suffice, indeed one cannot be satisfied with them. Instead, these texts issue a call to understand in a more complex and shifting way. Through them one can learn the value of an impatient waiting that heightens one's awareness, but also reserves the desire to intervene too quickly.

5 I would not claim this is appropriate for everyone in all contexts.

6 But it also exceeds the writer. As such it would be interesting to consider how Derrida's work might fit with Kate Rigby's claim, in 'Writing After Nature', that nature writing should be seen as 'embodying a literary practice of response: as such, we can truly say that writing comes second, following on from the other's call, while becoming in turn the locus of a new call, to and upon the reader' (np). 


\section{Re-inventing invention}

I would now like to turn to the question of what Derrida's writing may offer to the problem of recognising nature's agency, over and above the experience of reading. To recall, Plumwood argues for the need to develop accounts of agency that do not rest in the individual hyper-separate rational actor, but that instead draw upon concepts of interaction and mutuality, and importantly, the possibility of seeing what has been dismissed as merely accidental, 'as creative non-human agency', of seeing 'adaptation as intelligence' ('Nature in the Active'125). Under her account, those changes and expressions of creativity that are of key relevance are not those that can be traced back to a single, rational human actor. Rather possibility and causation, to echo Greenhouse's definition of agency, are thought in terms of the creative and active capacities of nature. As I noted above, the question of possibility can be taken up in a wide variety of ways within Derrida's work. In order to explore one approach in sufficient depth I have chosen to focus particularly on his exploration of the concept of invention. Since within this work, Derrida develops an account of transformation that does not arise through the active power of the rational individual, but rather depends upon the accidental and the surprising.

In his essay 'Psyche: Inventions of the Other', Derrida makes a claim that at first glance appears to be extremely unpromising. That is, he claims that invention always belongs to man as the inventing subject' (43). Indeed he claims that despite important variations within the concept, the connection between man and invention is 'a defining feature of very great stability' within the Western philosophical tradition (43). As he notes, within this tradition, "man himself, and the human world, is defined by the human subject's aptitude for invention' (44). In particular, this account of invention is strongly linked to the understandings of agency connected with the rational subject and to linear temporal schemas. For example, one of the ways serendipity is distinguished from invention is the extent to which inventions arise, not merely by chance, but can be understood as part of the logical progression of a certain body of knowledge. So while serendipity denotes a discovery made merely by chance and without reason, Derrida points out that since the Enlightenment there has been a much higher status granted to rationally guided inventive processes. He locates such views in the work of Leibniz and Kant, for example. As a result, insofar as invention has been understood to be in opposition to the serendipitous, that is, characterised by deliberation, agency and foresight, inventions have come to represent another step in the unfolding of rational progress. This links invention tightly both to ideals of linear progress and to its character as a peculiarly human capacity. Attempting to develop an account of nature's agency from within the 
framework of the Western concept of invention may, therefore, run into similar problems as those discussed above in relation to rethinking nature's agency from within the framework of linear time.

However, despite its unpromising heritage, Derrida nevertheless argues that the humanistic account of invention, which isolates this capacity within the domain of rational human acts, is not the only understanding of invention within the Western tradition. Rather, he exploits an apparent paradox within the tradition in order to open up the concept of invention beyond its role as guardian at the threshold between human and non-human. This paradox lies in the invention's dual character as firstly that which is repeatable, and thus able to become familiar or conventional. That is, an invention must introduce a technique or mechanism (understood in a broad sense) that can be shared and utilised by a wider community. But secondly, the invention must be that which breaks with all conventions, in that it must be new and surprising. That is, the invention must exceed the rational, logical, predictable unfolding of possibility, which has also been called 'progress'.

One way this paradox can be seen to be operating within the modern experience of invention is that while we may appear to be living in the golden age of invention, where an increasing amount of novelty is encountered on a daily basis, Derrida points out that many continue to dream of a reinvention of invention itself ('Psyche' 46). He argues that this desire arises because:

what is called a patentable 'invention' is now programmed, that is, subjected to powerful movements of authoritarian prescription and anticipation of the widest variety. And that is as true in the domains of art or the fine arts as in the techno-scientific domain ('Psyche' 46).

So despite the ever increasing availability of new electronic gadgets, new forms of entertainment and of communication, invention is, for the most part, not experienced as revolutionary or surprising. Rather than being experienced as the product of the rare combination of genius and luck, invention has become all too predictable. For Derrida then, 'our current tiredness results from the invention of the same and from the possible, from the invention that is always possible' (60). The 'possible' invention is one that can be planned for and anticipated. The future that it heralds does not differ significantly from the past, instead the invention is able, fairly unproblematically, to take its place within a logical progressive schema.

Nevertheless, Derrida argues that this 'invention of the same' does not fully accord with the concept of invention, as it has been thought in the Western tradition. Since if invention were only an invention of the same, then 'invention could be in conformity with its concept, with the dominant feature of the word 
and concept "invention", only insofar as, paradoxically, invention invents nothing' ('Psyche' 60). He admits that it is a necessary characteristic of invention that it conform to certain conventions. For example, a new object or method must be recognised by others as significant and useful if it is to be granted the status of invention. In this sense the invention cannot be singular or idiosyncratic but must be able to be utilised more generally. The invention must therefore offer a new capacity or ability that is repeatable by others. However, it remains the case that a true invention is expected to be disruptive and unpredictable. Indeed, the attempt to render invention neat and predictable does not actually fit with the perceived notion of what an invention is. Derrida writes instead that 'an invention always presupposes some illegality, the breaking of an implicit contract; it inserts a disorder into the peaceful ordering of things, it disregards the proprieties' (25). Far from appearing as always straightforwardly realisable, he argues that 'an invention has to declare itself to be the invention of that which did not appear to be possible' (60). That is, 'the only possible invention would be the invention of the impossible' (60).

By claiming that a true invention is 'impossible', Derrida is not claiming that they never occur. Rather, he claims that the impossible invention cannot be comprehended from the perspective of a calculable temporality. In its imperative to be disruptive and seemingly 'impossible,' the invention must break with an experience of time as comfortable and predictable. Indeed, he argues that there will be invention only on condition that the invention transgress, in order to be inventive, the status and the programs with which it was supposed to comply' ('Psyche' 41). An invention should not, therefore, be a simple fulfilment of what is already thought to be possible. Instead, the invention is what does not appear to take place in the normal order of things. So rather than representing a point along an infinite line of progress, Derrida suggests that the 'impossible' invention is better understood as 'an inaugural event' (28). In order to draw out what he might mean here, I will present a brief overview of how the concept of the event' has been approached within the phenomenological tradition, drawn from Françoise Dastur's essay 'Phenomenology of the Event: Waiting and Surprise'.

For Dastur, 'the event in the strong sense of the word is ... always a surprise, something which takes possession of us in an unforeseen manner, without warning, and which brings us towards an unanticipated future' (182). The event then, in Derrida's sense, is not one of the simple daily occurrences that make up the cycle of our lives. Rather, the event refers to those happenings that dislodge the anticipations and expectations that we have in regard to the future. Thus to be an event, an invention must disrupt the tendrils of anticipation that presume to know in advance what the invention would be. Reinventing invention thus requires developing a different relation to the future. Moreover, the disruptive effects of the event are not limited to social projections of the future, but extend 
into a society's shared heritages and traditions. As Heidegger has suggested, the possibilities we see in the future are projected from one's 'having-been' (18, 20). The impossible invention, however, exists as 'the event of a novelty that must surprise, because at the moment when it comes about, there could be no statute, no status, ready and waiting to reduce it to the same' ('Psyche' 43). In this case, no having-been is available to enfold the invention within shared pre-understandings. So while an invention that could be anticipated would be one that conformed to a society's shared history, the invention, as event, would happen beyond this prior experience. It would be surprising rather than reassuring, and thus not immediately graspable in relation to its usefulness or within common sense. It is for this reason that Dastur contends that the event 'does not happen in a world - it is, on the contrary, as if a new world opens up through its happening' (182).

In breaking with the world, the impossible invention is also that which offers the possibility of breaking with Western conceptions of linear time. This is, in part, because the transformation that produces an impossible invention is just as much a transformation of linear time. As Derrida argues in Spectres of Marx, the event cannot be thought 'as long as one relies on a general temporality or an historical temporality made up of the successive linking of presents identical to themselves and contemporary with themselves' (70). Instead, as Dastur suggests, the event 'introduces a split between past and future and so allows the appearance of different parts of time as dis-located' (182). She thus argues that the event is

irremediably excessive in comparison to the usual representation of time as flow. It appears as something that dislocates time and gives a new form to it, something that puts the flow of time out of joint and changes its direction (182).

Or as Derrida writes in Spectres of Marx, 'what is coming, in which the untimely appears, is happening to time but it does not happen in time' (77). 'Time' should here be specifically understood as linear time. That is, as that which is calculable and predictable, where the future is felt to be something that can be planned and meaningfully anticipated. ${ }^{7}$ Thus above and beyond its disruption of social expectations and preconceptions, Derrida suggests that the invention, as event, disrupts linear time itself.

7 Werner Hamacher suggests that this distinction between the future as possible and impossible can be understood as two 'times' 'a time that renders possible and one that renders impossible this very rendering' (174). However, one problem, which I only have the space to gesture towards here, is that both Derrida and Hamacher describe the time that is not predictable as 'not time' or 'atemporal'. While I cannot go into this problem in more detail, it is important to remember that an unpredictable future is only 'not time' from the perspective of a hegemonic Western understanding of time. That is, it is important not to mistake a retemporalisation as an absence of time, in part, because it assumes that Western conceptions of time are simply 
How, then, might the impossible invention transform understandings of agency, as a result of its disruption of dominant conceptions of linear time? To re-iterate, the impossible invention, which accords with the Western concept of invention despite its paradoxical character, cannot take place within a temporal scheme where the past provides a supportive interpretive structure or where the future can be anticipated. Crucially, this means that neither the agent's previous knowledge, nor their capacity to deduce logical consequences is useful here. Instead, what one finds in regard to the impossible invention - the invention as event - is that it is not something that can be actively and consciously invented by a subject according to a preconceived plan and with predictable effects. Instead, Derrida argues that to consciously invent would only be to invent on the basis of the possible, of the familiar. In contrast, the event is always something that happens to a subject, something which happens upon them and catches them unaware. As Dastur explains 'one does not decide freely to change one's world, or to become converted. We can speak of the event neither in the active nor in the passive voice' (186). Consequently, the self-directed subject with its clear anticipations of the future is ill-equipped to deal with the disorientation of the invention as event. This suggests that the invention-as-event is not an account of invention as a fully conscious activity of the self.

This does not mean, however, that one is absolutely passive in regard to the event. Interestingly, Dastur suggests that the event 'can change us and even "happen" to us only if we are in the right disposition' (186). The more embedded one is in traditions or habits, the less one is able to positively experience and welcome the difference such inventions herald. A more promising disposition may lie in welcoming the disorientation of the event as an opportunity to be extended and transformed by the unexpected character of this experience. Thus, in as much as this disposition can be cultivated, there may be room for activity and agency. Even so, the possibility of breaking with sedimented habit is not primarily in the hands of the subject, but depends upon the unexpected dislocations brought about through one's interactions with others. This is perhaps one reason why Derrida terms this type of invention 'the invention of the other,' in opposition to the 'invention of the same' ('Psyche' 55). So rather than the agent of invention being understood as outside of, or external to the world, under this account, the agent is passive insofar as they are dependent upon a surprising and accidental creativity to intervene within their world and transform it. This suggests that the 'agency' inherent within the act of invention is a strange intertwining of activity and passivity.

the time. Thus, the untimely should not to be understood as not time simply because it is not calculable and predictable. The question of to what extent Derrida's work might fall into the trap of universalising a particular cultural account of time must remain an open one for the time being. 
Importantly, Derrida's deconstruction of the concept of invention does not destroy the term altogether. But neither is this notion of invention 'new'. Rather, it is an understanding faithful to the concept's histories and traditions, which nevertheless opens it up and enables it to mean something else, and something more. This is important because as Plumwood argues 'we can't just strike out with a brand new story with brand new characters, or no story at all, and hope to make sense of where we are' ('Nature as Agency' 27). Instead Derrida's work on invention suggests a way of challenging our most basic assumptions through a closer analysis of the paradoxes already inherent within them. In particular, the paradox of agency, as it plays out within the concept of invention, is that the creative act is never solely within the capacity of the rational agency. Instead it is always an interaction, a mutuality and the instigator is never the individual rational self, but is rather the intervention of an other.

Consequently, what Derrida's work on invention suggests, is that while invention (as the invention of same) remains tied to an anthropocentric idealisation of the rational subject, invention also calls, from within its heritage and tradition, to be re-invented (as the invention of the other). In his essay, Derrida focuses on a poem by Francis Ponge, Fable, in order to articulate what this invention of the other might look like. Crucially, as was discussed above, while the invention must partake in an event-like structure, its character as a new, repeatable, shared capacity, means that the invention cannot only consist in the event. Rather the invention must combine a disruptive temporality and a more stabilised and predictable experience of time. That is, while the event happens only once, unique and singular and the institutionalised possibility is endlessly repeatable, the invention must be both. As Derrida writes, inventions 'imply both a first time and every time, the inaugural event and iterability' (51). However, as he has argued elsewhere, there is no absolute distinction between iterability and the possibility of the new. Within each iteration there is the chance that the repetition will not go as expected. Thus he explores how the repetition of Ponge's poem within a variety of contexts has the potential to open up new interpretations or experiences of the poem.

What I find most interesting, however, to return to the question of nature's agency, is how Derrida's account of invention might enable one to locate an 'invention of the other' within the processes of evolution. Far from being rejected as merely accidental, chaotic, or random (see Plumwood, 'Nature in the Active' 125), evolution could represent just that kind of invention that has the event-like power of transforming the world. In particular since, unlike the pure event, the accidents of evolution do not arise as a singularity that cannot be repeated. Rather, it is precisely the repetition necessary to reproduction that opens all living organisms to the ever-present possibility that they may reproduce in ways both unintended and unexpected. Indeed it is the very 
possibility that the extraordinary may arise from within the ordinary, not in opposition to it, that is one of the key elements of the (im)possibility of the invention of the other. Further, while being passive in regard to these changes, it is the species that are most able to welcome them, that are the most adaptable and resilient, that will be most able to thrive. Importantly, seeing evolution as invention enables the recognition of these changes as creative, rather than being produced like 'clockwork'. The changes that occur within nature become relevant and significant, thus affirming that nature does indeed have time (even while this may not be linear time). But more importantly, what this suggests is that we might understand the intertwining of activity and passivity, which characterises the processes of evolution, as a form of agency.

The key aim of this article has been to argue that challenging Western conceptions of time as linear is a key component of reworking Western conceptions of agency. I have suggested that Western understandings of linear time should not be used unreflectively as a guide for exploring conceptions of agency if one hopes to rewrite nature as a powerful creative actor. Indeed, I have discussed how linear time's connection to notions of rational progress helps to exclude nature, and those humans associated with nature, both from the capacity to have time and the ability to exercise agency. Rather than seeking to include nature within the concept of linear time, I have argued that both time and agency have to be rethought. Through an analysis of Derrida's work, I have suggested that a non-linear time, marked by a certain disjointedness, may be a more appropriate candidate. Particularly since within this account, change and creativity are not linked primarily to forethought and logical calculation, but rather to the surprising and the accidental. In this way, the changes that are deemed relevant, the changes that are deemed 'causes', are not those initiated by a rational actor, but rather are those that happen to the subject, those that throw the subject into a new world. It is under this account that, within the shifting changes, adaptations and creativities that happen to all life in the process of evolution (nature's 'form of wisdom' as Plumwood describes it), one may indeed be able to discern an inventing nature.

Michelle Bastian has recently completed her PhD in Philosophy at the University of New South Wales. Her work focuses on the use of concepts of time within community practices of inclusion and exclusion. 


\section{Acknowledgements}

This article was written while I was a Visiting Scholar at the Centre for Women's and Gender Studies at the University of British Columbia. Thanks to the Centre for their generosity in hosting me and for providing a wonderful environment in which to work. It was then revised while my partner and I were in the midst of a bicycle tour from Vancouver to California. So thanks to Paul for hanging around in San Francisco for a week while I worked. I would also like to thank the wonderful editors of the Eco-Humanities Corner for providing me with the opportunity to develop my work in new directions and for their insightful comments. Thanks also to the anonymous reviewers for their comments, which not only made this article stronger, but have also provided new directions in which to push my work.

\section{Works Cited}

Bastian, Michelle. Communities Out of Joint: An Examination of the Role of Temporality in Rethinking Community. PhD Thesis, University of New South Wales, 2009.

Dastur, Françoise. 'Phenomenology of the Event: Waiting and Surprise.' Hypatia 15.4 (2000): 178-89.

Derrida, Jacques. 'The Animal That Therefore I Am (More to Follow)'. Trans. David Wills. Critical Inquiry 28.2 (2002): 369-418.

-. 'Negotiations.' Negotiations: Interventions and Interviews, 1971-2001. Ed. Elizabeth Rottenburg. Standford, California: Stanford UP, 2002. 11-40.

- 'Psyche: Inventions of the Other.' Trans. Catherine Porter. Reading De Man Reading. Eds. Lindsay Waters and Wlad Godzich. Minneapolis: U of Minnesota P, 1989. 25-65.

- Spectres of Marx: The State of the Debt, the Work of Mourning, and the New International. Trans. Peggy Kamuf. New York: Routledge, 1994.

Fabian, Johannes. Time and the Other: How Anthropology Makes its Object. New York: Columbia UP, 1983.

Gell, Alfred. The Anthropology of Time: Cultural Constructions of Temporal Maps and Images. Oxford: Berg Publishers, 1992.

Greenhouse, Carol J. A Moment's Notice: Time Politics across Cultures. Ithaca and London: Cornell UP, 1996. 
Hamacher, Werner. 'Lingua Amissa: The Messianism of Commodity-Language and Derrida's Specters of Marx.' Ghostly Demarcations: A Symposium on Jacques Derrida's Specters of Marx. Ed. M. Sprinker. London: Verso, 1999. 130-178.

Heidegger, Martin. Being and Time: A Translation of Sein Und Zeit. 1953. Trans. Joan Stambaugh. Albany: SUNY Press, 1996.

McKibben, Bill. 'Worried? Us?' Granta 83 (Autumn 2003): 7-12.

Plumwood, Val. 'Nature as Agency and the Prospects for a Progressive Naturalism.' Capitalism Nature Socialism 12.4 (2001): 3-32.

-. 'Nature in the Active Voice.' Australian Humanities Review 46 (2009): 113129. http://epress.anu.edu.au/ahr/046/pdf/eh03.pdf Accessed 19 October 2009.

Rigby, Kate. 'Writing After Nature.' Australian Humanities Review 39-40 (2006). http://www.australianhumanitiesreview.org/archive/Issue-September-2006/ rigby.html Accessed 19 October 2009.

Rose, Deborah Bird. Dingo Makes Us Human: Life and Land in an Australian Aboriginal Culture. Cambridge: Cambridge UP, 2000.

- 'To dance With Time: A Victoria River Aboriginal Study.' The Australian Journal of Anthropology. 11:3 (2000): 287-296. 